\title{
Una excelente edición de Juan Ruiz de Alarcón*
}

Es éste el primer tomo de las Obras Completas de Juan Ruiz de Alarcón que está preparando el erudito profesor español, residente en México, don Agustín Millares Carlo. La edición comprenderá tres volúmenes y en ellos se incluirán todas las obras, dramáticas y no dramáticas, escritas por el ilustre mexicano, como asimismo, las que se le han atribuido.

En el prólogo, el autor, después de resumir brevemente la vida de Alarcón, se refiere a las comedias que fueron escritas en colaboración con otros escritores, sobre todo Tirso de Molina, y promete abordar el problema de dichas colaboraciones en el prólogo del tomo tercero. Estudia también la cronología de las comedias, en particular las hipótesis esbozadas por Henríquez Ureña, Reyes y Castro Leal. De interés especial es la del lamentado Courtney Bruerton, amplio conocedor de la comedia española (pág. xxix). No nos dice el prologuista en qué forma llegó a sus manos esta cronología. ¿Es que el erudito norteamericano se la proporcionó por carta? Alude Millares de vez en cuando a las teorías de Bruerton, especialmente al indicar las fechas de varias comedias, pero sería dato de no poco interés saber en qué se fundó la cronología del gran investigador, notable siempre por la solidez de su erudición.

En la tercera parte de su prólogo Millares describe la versificación con mucho cuidado y bastantes detalles. Indica cada clase de estrofa (sonetos, octavas reales, quintillas de cada una de las cuatro combinaciones empleadas por Alarcón, décimas, etc.). También enumera todos los

* Obras Completas, Tomo I, Teatro. Edición, prólogo y notas de Agustín Millares Carlo. Introducción de Alfonso Reyes. [Biblioteca Americana], Fondo de Cultura Económica, México-Buenos Aires, 1957. 
tipos de romances ( 77 combinaciones de asonancias), señalando los lugares en donde se encuentra cada estructura estrófica. Todo esto ha de interesar a los investigadores que tengan una afición especial por cifras y menudencias. Pero puesto que una enumeración de los metros empleados precede a cada comedia y el editor indica en las notas todos los cambios de metro, nos parece que sobran tantos pormenores. La versificación de Alarcón no ofrece ni la variedad ni la originalidad que encontramos en Lope o en Tirso.

Desaprueba Millares el uso de la palabra "lira" empleada por el profesor Morley en su excelente estudio sobre los metros de Alarcón, y por otros investigadores. Prefiere (no explica por qué) la denominación "estrofas aliradas". Al fin, en su prólogo, explica los criterios seguidos en esta edición: "En términos generales, el criterio por nosotros adoptado es conservador. Nos hemos, en efecto, esforzado por mantener, en las comedias incluidas en nuestros dos primeros volúmenes, siempre que ello nos ha parecido posible y justificado, el texto de las ediciones de I628 y I634" (pág. xliv). El texto "se presenta puntuado a la manera actual, regularizado en lo tocante al uso de las mayúsculas; separadas las palabras mal unidas, y unidas las indebidamente separadas; corregidas las erratas evidentes, y modernizada la ortografía, excepto en los casos en que la modernización implicaría cambiar la forma de las palabras". (pág. xlvi). Sigue la enumeración de las palabras más importantes cuya ortografía original se ha conservado.

Añade el editor acotaciones escénicas y apartes, pero sin poner las añadiduras en corchetes, ni indica en las notas que no se encuentran en el texto original. Su aseveración de que "Hartzenbusch dividió en escenas las comedias con excepción de tres: La Cueva de Salamanca, Ia Mangonilia de Melilla y La Prueba de las promesas [Esta división] "la hemos adoptado y extendido a las tres piezas mencionadas" (pág. xliv), parece hacer caso omiso de que Hartzenbusch tampoco dividió la comedia alarconiana El anticristo ni la de colaboración Algunas bazañas, etc.

No nos ha sido posible cotejar todos los textos con los originales, pero por lo que hemos podido examinar parece que todo se ha reproducido fielmente dentro de las normas adoptadas.

Inclúyense en este tomo las dedicatorias y los prólogos de las ediciones de 1628 y de 1634 y nueve de las comedias: Las ocho que aparecieron en la primera parte y la primera de la Parte segunda. Cada pieza va precedida de una noticia, la enumeración de los metros empleados, y una bibliografía de las ediciones más importantes. En el caso de Las paredes 
oyen, Millates nos señala también traducciones y estudios de la comedia. No sabemos si quiso darnos todas las ediciones y traducciones de las comedias; es posible que analice otras en las bibliografías prometidas en el tercer tomo. El hecho es que existen algunas que no se dan aquí, y que quisiéramos mencionar ahora:

En el tomo II de Teatro selecto, antigua y moderno, nacional $y$ extranjero (Barcelona, I866-I868), se encuentran Las paredes oyen (págs. 35-63), Mudarse por mejorarse (págs. 65-92), Los favores del mundo (págs. I23-154), y El semejante a sí mismo (págs. 2 II-238).

De la comedia La industria y la suerte, con el título La suerte y la industrita, hay una suelta, s.l.n.a., en la biblioteca de la Universidad de Friburgo, en Alemania. Está atribuida a Cubillo, pero sobre el nombre de éste hay una nota manuscrita que dice "Alarcón y Mendoza". Según el catálogo de Cambronero, la Biblioteca Municipal de Madrid posee una copia manuscrita con aprobaciones de 1809 y I8I7.

De Mudarse por mejorarse hay una traducción francesa por Alphonse Royer, Changer pour trouver mieux (Paris, I865).

Carlos Bo tradujo Las paredes oyen al italiano en Teatro spagnolo (Milano, r94r). Escribe Millares (pág. 203) que había un ejemplar ma. nuscrito de esta pieza, al parecer autógrafo, en la Biblioteca del Duque de Osuna, el cual no figuró entre los manuscritos adquiridos por la Biblioteca Nacional de Madrid. Según el catálogo preparado por Joaquín Montaner, La colección teatral de don Arturo Sedó en Barcelona (Barcelona, I95I), hay en la biblioteca particular de Sedó un ejemplar manuscrito de la Biblioteca de Osuna. ¿Es posible que sea el mismo?

Todo es ventura: Hállase en la Biblioteca Palatina, en Italia, un manuscrito de la primera mitad del siglo xvil que tiene "molte varianti" del texto impreso por Hartzenbusch en la $B A E$, "specialmente nella terza giornata", Antonio Restori, en Studi di Filologia Romanza, VI, pág. I3). Publicó Hartzenbusch una edición completa estereotípica en Madrid, 1845.

Publicóse $E l$ desdichado en fingir en el segundo tomo de Teatro de Juan Ruiz de Alarcón (París, I884), además de las tres comedias citadas por Millares.

Los empeños de un engaño se incluye en el tomo segundo de la Colección general de comedias escogidas del teatro antiguo español (Madrid, I829).

Siguen a los textos I95 páginas de "variantes, erratas y notas" todas en tipo menudo. Las variantes son las señaladas por Hartzenbusch y otros editores (Henríquez Ureña, Reyes, Bourland, et al.). Las erratas, por lo 
general tipográficas, son las "evidentes" del texto original, corregidas por el editor. Nos parece de poca necesidad y de escaso interés indicar que Hartzenbusch escribe "u obligarme" en vez de "o obligarme" del original o que Hartzenbusch y Henríquez Ureña cambian "no lo quiere" por "no le quiere". Y eso que mucho se debe a las labores de Hartzenbusch.

Las notas son copiosísimas y de mucho valor e interés. Clarifican algunas palabras oscuras (y otras no muy oscuras), aclaran alusiones a lugares, personajes y sucesos importantes, explican las costumbres de la época, y con mucha frecuencia comparan el uso de tal o cual palabra o cons. trucción sintáctica con otros análogos que se encuentran en las comiedias del mismo Alarcón o de otros dramaturgos. Por medio de varias referencias de una parte a otra de cada comedia, dilucídanse los argumentos de las piezas. Sin duda las notas son la parte más importante y más útil del libro. Quizás en una obra tan pródiga y tan detallada, no sea posible, pero si lo fuera, sería de gran valor un registro de las palabras comentadas en estas extensas notas.

Si hubiera algo que observar es el arreglo de la bibliografía. Como nos explica el editor, la descripción bibliogtáfica de las ediciones que contienen dos o más comedias de Alarcón se incluirá en el tomo III en la Bibliografía A, y "la enumeración, con extractos y análisis de los trabajos que sobre nuestro autor hemos logrado consultar" aparecerá en la Bibliografía $B$. Refiérese el editor a obras que han de incluirse en estas dos bibliografías como "Bibliografía A, núm. 5", "Bibliografía B, núm. 93", etc. Al lector le resulta dificultoso no disponer de las bibliografias, ni saber de un libro citado más detalles que, por ejemplo, "Reyes (1939), Bibliografía B, núm. I 7 ". ¿No habría sido mejor omitir en este primer tomo la única comedia tomada de la segunda parte e incluir en su lugar las bibliografias? De este modo el lector las hubiera tenido a mano para consultarlas desde el primer momento.

Alfonso Reyes contribuye con una amena introducción, en la cual nos da un breve bosquejo de la vida y del carácter de Alarcón. Vuelve a tratar la cuestión de su mejicanismo, siempre espinosa y de cuyo proceso disponemos un útil trabajo escrito por Antonio Alatorre. Reyes comparte las ideas de Henríquez Ureña y escribe que "en toda galería mexicana, corresponde a Alarcón el primer capítulo. Su obra es la primera manifestación eminente y de valor internacional sobre eso que ya puede llamarse el espíritu mexicano. El cual es muy anterior a nuestra autonomía política $\mathrm{y}$, a pesar de los altibajos y contingencias históricas, sigue siendo nuestra 
norma y nuestro ideal tal como se muestra en Alarcón" (pág. xv). Admite que "en la obra de Alarcón apenas hay evocaciones de ambiente miexicano y americano en general, ...Pero es, en cambio, constante la penetración de cierta atmósfera moral y sentimental. Tal atmósfera es ya mexicana" (pág. xvii). Aunque con esto no estamos completamente de acuerdo sí lo estamos con la aseveración de que "ni en México $n i$ en España, se le hallan antecedentes a Alarcón; ni en España ni en México, descendencia inmediata" (pág. xviii). Al fin y al cabo no importa que haya nacido Alarcón en México ni que tanto los españoles como los mexicanos le hayan hecho suyo. Es un artista que pertenece al mundo, y si el afecto o el orgullo de los eruditos mexicanos (Reyes, Castro Leal, Jiménez Rueda, y otros) los lleva a estudiar sus obras y su vida, gana todo el mundo.

En cuanto a errores tipográficos, nos sorprende encontrar muy pocos en un libro tan extenso y tan detallado. No los hemos buscado con especial cuidado, pero algunos de redacción que hemos notado son los siguientes:

Pág. xxvii: "Quien engaña más a quien o Los dos locos amantes (Sevilla, Francisco Leefdael, sin año)". ¿No debe ser "Quien mal anda mal acaba o Los dos locos amantes"? La crueldad por el bonor y El dueño de las estrellas se encuentran en la segunda parte, no en la primera. La fecha de la primera representación de Las paredes oyen es 1617 , en vez de 1627 .

Pág. 14: V29, "crüel" en vez de "cruel".

Pág. I Io: El último verso del primer acto es 966 , no 965 . El pasaje de redondillas con que empieza el segundo acto es 967-roI8.

Pág. 20r: En la nota segunda, "núm. 20" debe ser "núm. $2 \mathrm{r}$ ".

Pág. 203: Dentro del pasaje de romance en $e-0$, hay una redondilla: vv I3I4-1317.

Pág. 386: Entre los metros empleados en el acto tercero, "seis estrofas aliradas" debe leerse "siete estrofas aliradas".

Pág. 870-87I: Entre los variantes leemos "I7r.-me lloréis. Véase la nota a este verso" y "2369-grande. Véase la nota a este verso". No encontramos las notas correspondientes.

Pág. 976. El autor del artículo sobre los teatros de México es Harvey Leroy Johnson, no Johnson Harvey Leroy. El autor de Multiple Stage, etc. es W. H. Shoemaker, no Schoemaker. Pero éstos y otros que pueden encontrarse no quitan nada al mérito de esta magnífica obra, que nos of rece tanto los textos originales de Alarcón como la segura erudición de 
un hombre de letras que conoce, quizás más a fondo que nadie, la obra de Alarcón.

El tomo está dedicado a la memoria del lamentado erudito Courtney Bruerton, quien - de vivir-hubiese podido gozat de una obra que en nada desmerece al lado de sus propios estudios maestros.

Walter Poesse, Universidad de Indiana. 